\title{
Selection of lactic acid bacteria for exopolysaccharide production
}

\author{
Ivy C. Emnace ${ }^{1 *}$ and Erlinda I. Dizon ${ }^{2}$
}

\begin{abstract}
An important source of natural alternative to commercial additives that are commonly extracted from plants and animals is the exopolysaccharide (EPS) produced by lactic acid bacteria (LAB). A screening for EPS production by Lactobacillus delbrueckii, Lactobacillus rhamnosus NBRC 3425 and Weisella paramesenteroides was conducted to identify which among these three LAB would produce the highest yield of EPS. The test organisms were grown in a Semi-defined Medium (SDM) of Sanchez et al (2006) with some modifications. EPS production was confirmed by the formation of precipitate after mixing the broth medium with $95 \%$ absolute ethanol. Results of total sugar analysis by phenol-sulfuric acid assay revealed that estimated EPS yield of $L$. rhamnosus NBRC 3425 was significantly higher at $p<0.05$ than those of $W$. paramesenteroides and L. delbrueckii ssp. lactis with values of $0.1355 \mathrm{~g} / \mathrm{L}, 0.0652 \mathrm{~g} / \mathrm{L}$ and $0.0544 \mathrm{~g} / \mathrm{L}$, respectively even though their viable count did not differ significantly from each other. Correspondingly, the $\mathrm{pH}$ of $L$. rhamnosus NBRC 3425 media was also significantly higher $(\mathrm{pH} 4.03)$ than $L$. delbrueckii ( $\mathrm{pH} 3.60)$ and W. paramesenteroides ( $\mathrm{pH} 3.83)$.
\end{abstract}

Keywords: exopolysaccharide, lactic acid bacteria, phenol-sulfuric acid assay, Semi-defined medium (SDM), total sugar

\section{INTRODUCTION}

The global market for hydrocolloids which includes many polysaccharides, is still dominated by plant and algal polysaccharides (eg, starch, galactomannans, pectin, carrageenan and alginate) (Imeson 2010). The animal derived proteinaceous hydrocolloids gelatin and casein are also utilized. The functional properties in foods of these polymers are determined by subtle structural characteristics. However, these polysaccharides may not always be readily available in the quality needed or their rheological properties may not exactly match

Department of Food Science and Technology, Visayas State University, Visca, Baybay City, Leyte, 6521 - A Philippines

\footnotetext{
* Corresponding Author. Address: Department of Food Science and Technology, Visayas State University, Visca, Baybay City, Leyte, 6521 - A Philippines; Email: ivy.emnace@vsu.edu.ph DOI: $10.32945 /$ atr 4025.2018
} 
those required. Most of the plant carbohydrates used are chemically modified to improve their structure and rheological properties (De Vuyst \& Degeest 1999, Roller \& Dea 1992, Tombs \& Harding 1998). Their use is hence strongly restricted. For instance, the European Union (EU) allows their addition only in some food products such as bakery products (Abbas et al 2010, De Vuyst \& Degeest 1999).

An alternative class of biothickeners are microbial exopolysaccharides (EPS) (De Vuyst \& Degeest 1999). Bacterial exopolysaccharides (EPS) show great diversity and functions, and their production is not limited by taxa (Nwodo et al 2012). A number of Lactic Acid Bacteria (LAB) can produce a variety of long chain sugar polymers, called EPS which are mainly employed for the production of fermented dairy products. Most LAB-producing EPS belong to the genera Streptococcus, Lactobacillus, Lactococcus, Leuconostoc, and Pediococcus (Florou-Paneri et al 2013). They are synthesized either extracellularly from sucrose by glycansucrases or intracellularly by glycosyltransferases from sugar nucleotide precursors (Florou-Paneri et al 2013, Ganzle \& Schwab 2009).

Sutherland (1990) found that ESPs are used because of their capacity to control the texture of foods and to prevent or reduce ice crystal formation in frozen foods. They may also influence the appearance and color as well as the flavor of prepared foodstuff. Bacterial cellulose is preferred over plant cellulose as it can be obtained in higher purity and exhibits a higher degree of polymerization and crystallinity index. It also has higher tensile strength and water holding capacity than that of plant cellulose (Chawla et al 2009, Shoda \& Sugano 2005). To date, EPS produced by $L A B$ have received increasing interest mainly because of their GRAS (Generally Regarded as Safe) status (Sutherland 1998). The GRAS and probiotic status of some lactic acid bacteria could provide impetus for more preference for their consumable EPS products (Badel et al 2011).

The greatest potential of bacterial EPS is related to their use in high-value market niches, such as cosmetics, pharmaceuticals, food ingredient, functional foods and biomedicine, in which traditional polymers fail to comply with the required degree of purity or lack some specific functional properties (Freitas et al 2011). Therefore, the search for bacteria with high ESP and ESP conjugate (bioflocculants) yields is an ongoing process (Nwodo et al 2012, Mabinya et al 2012). This study aimed to select among three strains of lactic acid bacteria capable of producing higher yield of exopolysaccharide and evaluate possible factor/s affecting production of the biopolymer.

\section{MATERIALS AND METHODS}

\section{Lactic Acid Bacteria Isolates}

Pure cultures of Lactobacillus delbrueckii ssp. lactis and Weisella paramesenteroides were provided by the Food Microbiology Laboratory-Food Science Cluster, College of Agriculture, University of the Philippines Los Baños (UPLB), Laguna and Lactobacillus rhamnosus NBRC 3425 was provided by the National Institute of Molecular Biology and Biotechnology (BIOTECH), UPLB, Laguna, Philippines. The stock culture was maintained in MRS broth by monthly transfer and storage at $4^{\circ} \mathrm{C}$. 
Selection of lactic acid bacteria

\section{Culture Media for Exopolysaccharide Production}

The Semi-defined Medium (SDM) of Sanchez et al (2006) with some modifications was used to grow the test organisms for the production of exopolysaccharide with the following composition (in grams per liter). Dextrose, 20 (carbon source); Tween 80, 1; ammonium citrate, 2; sodium acetate, 5 ; $\mathrm{MgSO}_{4} .7 \mathrm{H}_{2} \mathrm{O}$, $0.1 ; \mathrm{MnSO}_{4}, 0.05 ; \mathrm{K}_{2} \mathrm{HPO}_{4}, 2$; Casamino Acid, 5 (instead of Yeast Nitrogen Base); Tryptone, 10 . Fifty (50) $\mathrm{ml}$ of the growth medium was dispensed to individual $250 \mathrm{ml}$ Erlenmeyer flask prior to sterilization for $15 \mathrm{~min}$ at $121^{\circ} \mathrm{C}$.

\section{Fermentation Conditions for Screening}

The bacterial isolates were screened for their ability to produce EPS by inoculating active cultures in a sterile $50 \mathrm{ml}$ modified Semi-Defined Medium (SDM). Each flask was inoculated with $2 \% 10^{8} \mathrm{CFU} / \mathrm{ml}$ of $16-18$ hour old inocula and incubated at their respective optimum temperature for growth [Weisella paramesenteroides $\left(30^{\circ} \mathrm{C}\right)$, Lactobacillus delbrueckii ssp. lactis and Lactobacillus rhamnosus NBRC $3425\left(37^{\circ} \mathrm{C}\right)$ ] for 48 hours. The medium contained $2 \%$ (wt/vol) glucose as the carbon source, with an initial $\mathrm{pH}$ of 6.2 .

\section{Extraction of Exopolysaccharide}

Cold absolute ethanol extraction was adopted in the extraction of EPS using the method of Rimada and Abraham (2003) with some modifications. The 48-hour old bacterial cultures in $50 \mathrm{ml}$ SDM broth was centrifuged (Hermle, Germany) at $6000 \mathrm{rpm}$ for $15 \mathrm{~min}$ at $4^{\circ} \mathrm{C}$ to remove cell pellets. Then the supernatant was precipitated with double volume of $95 \%$ chilled ethanol and stored overnight at $4^{\circ} \mathrm{C}$ to allow precipitation of EPS. After overnight incubation, a second extraction was done as above. Finally, the mixture was re-centrifuged at $6000 \mathrm{rpm}$ for $15 \mathrm{~min}$ at $4^{\circ} \mathrm{C}$ to collect the crude EPS. The collected EPS was freeze-dried (GT2 Leybold-Heraeus, Germany) for 6-8 hours. The total carbohydrate present in the pellet was estimated by phenol-sulphuric acid assay (Dubois et al 1956).

\section{Test for Lactic Acid Production by LAB Culture}

The test organisms were grown in Glucose Yeast Peptone Agar (GYPA) with calcium carbonate. After $18-24$ hours of incubation at $37^{\circ} \mathrm{C}$, colonies were observed with the formation of clear zones which is an indication of acid production by the LAB.

\section{Viable Count Determination}

Total viable count of the test organisms previously grown in MRS broth at $37^{\circ} \mathrm{C}$ for 16-18 hours was determined prior to inoculation ( $2 \%$ inoculation rate) in the modified Semi-defined Medium (SDM) for exopolysaccharide production. Determination of viable cell counts was carried out by serial dilution up to $10^{-8}$ in sterile $0.1 \%$ peptone water and pour plating. Plates were incubated at incubation temperatures corresponding to the requirement of the test organism for 24-48 hours to obtain sufficient growth. Viable count was reported as colony forming unit (CFU/ml). 


\section{Estimation of EPS Yield}

Total polysaccharide content was measured by phenol-sulfuric acid assay using D-glucose as calibration standard (Dubois et al 1956). Equal volumes of sample and glucose standard were mixed with $5 \%$ phenol (JT Bakers, USA) in test tubes and then $2.5 \mathrm{~mL}$ of concentrated sulfuric acid (95-97\% Sigma-Aldrich, USA) was added. The solution was mixed in a gentle vortex and immediately soaked in ice water bath. After allowing the sample to cool for $30 \mathrm{~min}$, absorbance of the solutions was measured at 490nm using UV-VIS spectrophotometer (Shimadzu, Japan).

\section{pH Determination of Broth after Fermentation}

The $\mathrm{pH}$ pen was calibrated with $\mathrm{pH} 4.0$ and 7.0 buffer solutions. The final $\mathrm{pH}$ of the 48-hour fermented medium was measured directly using a digital $\mathrm{pH}$ pen (Milwaukee Instruments, series no. 110774).

\section{RESULTS AND DISCUSSION}

\section{Selection of Lactic Acid Bacteria for Exopolysaccharide Production}

In this study, the selection of EPS-producing LAB was based on published literatures. This is more focused on the selection of the LAB strain with good EPS producing ability. Cultures of Lactobacillus delbrueckii ssp. lactis, Lactobacillus rhamnosus NBRC 3425 and Weisella paramesenteroides were plated on Glucose Yeast Peptone Agar with calcium carbonate (Figure 1). Growth on the solid medium of the three Lactobacillus strains showed clear zones of all colonies which means that there is production of lactic acid typical of LAB.
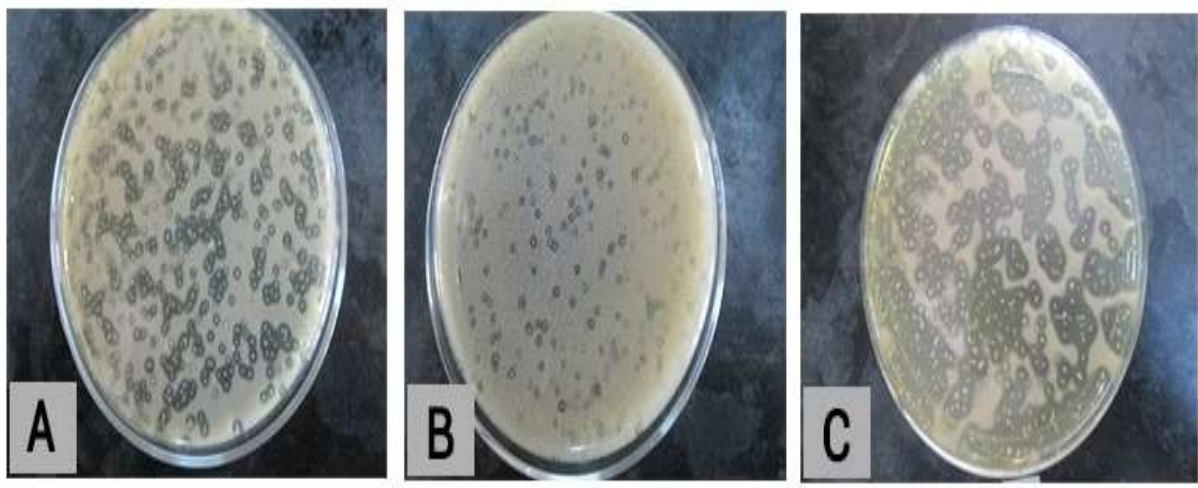

Figure 1. Lactic acid bacteria culture showing clear zones in GYPA with $5 \%$ calcium carbonate (a) Lactobacillus delbrueckii ssp. lactis (b) Weisella paramesenteroides (c) Lactobacillus rhamnosus NBRC 3425

\section{Estimated Exopolysaccharide Production}

Test organisms were grown in broth medium (modified SDM) with $20 \%$ glucose as the carbon source with an initial $\mathrm{pH}$ of 6.2 and incubation temperature of 
Selection of lactic acid bacteria

$37^{\circ} \mathrm{C}$ (L. rhamnosus NBRC 3425 and L. delbrueckii ssp. lactis) and $30^{\circ} \mathrm{C}(\mathrm{W}$. paramesenteroides). The Phenol-sulfuric acid assay revealed that the estimated EPS yield of $L$. rhamnosus NBRC 3425 was significantly different at $p \leq 0.05$ than those of $W$. paramesenteroides and $L$. delbrueckii ssp. lactis with values of $0.1355 \mathrm{~g} / \mathrm{L}, 0.0652 \mathrm{~g} / \mathrm{L}$ and $0.0544 \mathrm{~g} / \mathrm{L}$, respectively (Table 1 ). Different strains of bacteria have varying capacities to synthesize exopolysaccharide regardless of the medium, availability of nutrient, temperature, $\mathrm{pH}$, etc., where they are cultivated. Most bacteria produce EPS under all conditions, but the quantities and the composition of EPS are strain-dependent and affected by the nutritional and environmental conditions (Looijesteijn et al 1999). Biosynthesis of EPS differs among genera and is an energy-dependent process (Patel et al 2010).

Table 1.Mean viable count (cfu/ml), EPS production $(\mathrm{g} / \mathrm{L})$ of test organisms and final $\mathrm{pH}$ of modified Semi-Defined Medium

\begin{tabular}{lccc}
\hline \hline \multirow{2}{*}{ Test Organism } & \multicolumn{2}{c}{ Parameters } \\
\cline { 2 - 3 } & Final pH & EPS Production(g/L) & $\begin{array}{c}\text { Viable Count } \\
(\mathrm{cfu} / \mathrm{ml})^{\mathrm{ns}}\end{array}$ \\
\cline { 2 - 3 } W. paramesenteroides & $3.83^{\mathrm{b}}$ & $0.0652^{\mathrm{b}}$ & $1.98 \times 10^{9}$ \\
L. delbrueckii ssp. lactis & $3.60^{\mathrm{c}}$ & $0.0544^{\mathrm{b}}$ & $2.63 \times 10^{9}$ \\
L. rhamnosus NBRC 3425 & $4.03^{\mathrm{a}}$ & $0.1355^{\mathrm{a}}$ & $2.26 \times 10^{9}$ \\
\hline \hline
\end{tabular}

The mean difference is significant at $p \leq 0.05$

Results agree with the findings of Macedo et al (2002) as reported by Tsuda (2013) where Lactobacillus rhamnosus RW-9595M exhibited the highest recorded yields of hetero-EPS (2.78g/L). In another study of Bergmaier et al (2003) a very high EPS concentration of $2.3 \mathrm{~g} / \mathrm{L}(2300 \mathrm{mg} / \mathrm{L})$ was obtained during $\mathrm{pH}$-controlled batch cultures of Lactobacillus rhamnosus RW-9595M in $8 \%$ whey permeate medium supplemented with $\mathrm{MgSO}_{4} \cdot 7 \mathrm{H}_{2} \mathrm{O}, \mathrm{MnSO}_{4} \cdot \mathrm{H}_{2} \mathrm{O}$, Tween 80 , and yeast extract for final concentrations of $0.5 \mathrm{~g} / \mathrm{L}, 0.05 \mathrm{~g} / \mathrm{L}, 1 \mathrm{~mL} / \mathrm{L}$, and $10 \mathrm{~g} / \mathrm{L}$, respectively.

\section{Relationship of Resulting $\mathrm{pH}$ with EPS Yield}

After 48 hours of incubation, the final $\mathrm{pH}$ of modified SDM decreased from 6.2 to 3.6 (L. delbrueckii ssp. lactis), 3.83 (W. paramesenteroides) and 4.03 ( $L$. rhamnosus NBRC 3425). It was observed that the medium exhibiting the least change in $\mathrm{pH}$ during fermentation produced the highest EPS yield. This decrease in $\mathrm{pH}$ during fermentative production is caused by the accumulation of gluconic, acetic or lactic acids in the culture broth (Kongruang 2008). The pH which is an important factor affecting EPS yield was significantly lower $(p \leq 0.05)$ in $L$. delbrueckii ssp. lactis, compared to $W$. paramesenteroides and L. rhamnosus 
NBRC 3425 (Table 1). The decrease of the medium's final pH correspondingly resulted in a significant decrease in EPS yield, because when acidification occurs resulting to lactate production, enzyme glycohydrolases are activated approximately at $\mathrm{pH} 5$ causing degradation of the EPS. The possible presence of glycohydrolases in the fermentation medium hydrolyzes EPS to monomers, causing such a decrease in EPS yield during prolonged fermentation (Yang et al 2010).

\section{Relationship of Growth and EPS Yield}

It has been reported that biosynthesis of EPS is growth-associated. Results of this study however, revealed that although there was no significant difference observed in the viable count of the test organisms a significant difference was noted in the EPS production of $L$. rhamnosus NBRC $3425(p \leq 0.05)$ from $W$. paramesenteroides and $L$. delbrueckii ssp. lactis. This could possibly imply that $L$. rhamnosus NBRC 3425 is a very good producer of EPS or it may not always be true that EPS production is growth-associated, although this claim still needs further elucidation. Pham et al (2000) reported that Manca de Nadra et al (1985) and Kojic et al (1992) observed both growth-associated and non-growth associated production kinetics. Gassem et al (1995) also found that there was no association between growth rate or acid production and polysaccharide production in different media by LAB (strains $\mathrm{CH} 15$, YB57, and YB58 and S. salivarius subsp. thermophilus ST3). Recently, Looijesteijn et al (1999) indicated an uncoupling of growth and EPS production when the production of EPS by L. lactis subsp. cremoris NIZO B40 was investigated. According to them, a possible explanation for this uncoupling is the fact that optimal conditions for EPS production and growth are not the same (Pham et al 2000).

\section{CONCLUSION}

The production of bacterial exopolysaccharide is directly affected by the $\mathrm{pH}$ of the medium where it is grown since lower $\mathrm{pH}$ favors degradation of the polysaccharide. Results of the present study revealed that $L$. rhamnosus NBRC 3425 produced a significant amount of EPS compared to $W$. paramesenteroides and $L$. delbrueckii ssp. lactis even if the viable count does not significantly vary from the two test organisms.

\section{ACKNOWLEDGMENT}

The authors gratefully acknowledge the Department of Science and Technology-Science Education Institute (DOST-SEI), Philippines for the research fund. We also thank the Institute of Food Science and Technology, National Institute of Molecular Biology and Biotechnology (BIOTECH) and the Animal and Dairy Sciences Cluster, University of the Philippines, College, Laguna for the facilities used in this research. 
Selection of lactic acid bacteria

\section{REFERENCES}

Abbas KA, Kahlil SK \& Hussin ASM. 2010. Modified Starches and their Usages in Selected Food Products: A Review Study. Journal of Agricultural Science, 2(2):1-11

Badel S, Bernardi T \& Michaud P. 2011. New perspectives for Lactobacilli exopolysaccharides. Journal of Biotechnology Advances, 29(1):54-66

Bergmaier D, Champagne CP \& Lacroix C. 2003. Exopolysaccharide production during batch cultures with free and immobilized Lactobacillus rhamnosus RW-9595M. Journal of Applied Microbiology, 95(5):1049-1057

Chawla PR, Bajaj IB, Survase SA \& Singhal RS. 2009. Microbial cellulose:Fermentative production and applications. Fermentative Production of Microbial Cellulose, Food Technology and Biotechnology, 47(2):107-124

De Vuyst $L$ and Degeest B. 1999. Heteropolysaccharides from lactic acid bacteria. FEMS Microbiology Reviews, 23(2):153-177

Dubois M, Gilles KA, Hamilton JK, Rebers P \& Smith F. 1956. Colorimetric method for determination of sugars and related substances. Analytical Chemistry, 28(3):350-356

Florou-Paneri P, Christaki E \& Bonos E. 2013. Lactic acid bacteria as source of functional ingredients. In: Kongo, M. (Ed). Lactic Acid Bacteria - R \& D for Food, Health and Livestock Purposes (p589-614). Intech

Freitas F, Alves VD \& Reis MAM. 2011. Advances in bacterial exopolysaccharides: from production to biotechnological applications. Trends in Biotechnology, 29(8):388-98

Ganzle MG and Schwab C. 2009. Ecology of exopolysaccharide formation by lactic acid bacteria: Sucrose utilisation, stress tolerance, and biofilm formation. In Ullrich M. (Ed). Bacterial Polysaccharides: Current Innovations and Future Trends (p263-278). Germany: Caister Academic Press

Giavasis I and Biliaderis C. 2006. Microbial Polysaccharides. In Biliaderis and Izydorczyk (Eds). Functional Food Carbohydrates (p167-213). USA, Florida, CRC Press

Imeson A (Ed). 2010. Food Stabilisers, Thickening and Gelling Agents, WileyBlackwell (pp343). London: John Wiley \& Sons Ltd

Kongruang S. 2008. Bacterial cellulose production by Acetobacter xylinum strains from agricultural waste products. Applied Biochemistry and Biotechnology, 148(1-3):245-256

Looijesteijn PJ, Van Casteren WHM, Tuinier R, Doeswijk-Voragen CHL \& Hugenholtz J. 2000. Influence of different substrate limitations on the yield, composition and molecular mass of exopolysaccharides produced by Lactococcus lactis subsp. cremoris in continuous cultures. Journal of Applied Microbiology, 89(1):116-122

Mabinya VL, Cosa S, Nwodo UU \& Okoh Al. 2012. Studies on bioflocculant production by Arthrobacter sp. Raats, a freshwater bacterium isolated from Tyume river, South Africa. International Journal of Molecular Sciences, 13(1):1054-1065

Macedo MG, Lacroix C, Gardner NJ \& Champagne CP. 2002. Effect of medium 
supplementation on exopolysaccharide production by Lactobacillus rhamnosus RW-9595M in whey permeate. International Dairy Journal, 12(5):419-426

Nwodo UU, Green E \& Okoh Al. 2012. Bacterial exopolysaccharides: functionality and prospects. International Journal of Molecular Sciences, 13(11):1400214015

Patel AK, Michaud P, Singhania RR, Soccol CR \& Pandey A. 2010. Polysaccharides from probiotics: New developments as food additives. Food Technology and Biotechnology, 48(4):451-463

Pham PL, Dupont I, Roy D, Lapointe G \& Cerning J. 2000. Production of exopolysaccharide by Lactobacillus rhamnosus $\mathrm{R}$ and analysis of its enzymatic degradation during prolonged fermentation. Applied and Environmental Microbiology, 66(6):2302-2310

Rimada PS and Abraham AG. 2003. Comparative study of different methodologies to determine the exopolysaccharide produced by kefir grains in milk and whey. Lait, 83(1):79-87

Roller S and Dea LCM. 1992. Biotechnology in the production and modification of biopolymers for foods. Critical Reviews in Biotechnology, 12(3):261-277

Sanchez JI, Martinez B, Guillen G, Jimenez-Diaz R \& Rodriguez A. 2006. Culture conditions determine the balance between two different exopolysaccharides produced by Lactobacillus pentosus LPS26. Journal Applied and Environmental Microbiology, 72(12):7495-7502

Shoda M and Sugano Y. 2005. Recent advances in bacterial cellulose production. Biotechnology and Bioprocess Engineering, 10:1-8

Sutherland IW. 1998. Novel established application of microbial polysaccharides. Trends in Biotechnology, 16(1):41-46

Sutherland IW. 1990. Biotechnology of Microbial Exopolysaccharides. Cambridge University Press, Cambridge, United Kingdom. (p171)

Tombs M and Harding SE (Eds). 1998. An introduction to polysaccharide biotechnology. In Sutherland, I.W. Biochemistry and Molecular Biology Education (p183). London: Taylor and Francis

Tsuda H. 2013. Exopolysaccharides of Lactic Acid Bacteria for Food and Colon Health Applications. In Kongo, M. (Ed). Lactic Acid Bacteria - R \& D for Food, Health and Livestock Purposes (p515-538). Intech

Yang Z, Li S, Zhang X, Zeng X, Li D, Zhao Y \& Zhang J. 2010. Capsular and slimepolysaccharide production by Lactobacillus rhamnosus JAAS8 isolated from Chinese sauerkraut: Potential application in fermented milk products. Journal of Bioscience and Bioengineering, 110(1):53-57 